\title{
Early probing in congenital naso-lacrimal duct obstruction
}

\author{
Amer Y. Rajab \\ Department of surgery, College of Medicine, University of Mosul, Mosul, Iraq. \\ Correspondence: Amer Y. Rajab. ameryahya50@yahoo.com.
}

(Ann Coll Med Mosul 2018; 40 (1): 27-30).

Received: $3^{\text {th }}$ Jan. 2012; Accepted: $8^{\text {th }}$ Dec. 2013.

\section{ABSTRACT}

Aim: To evaluate the role of early probing in congenital naso-lacrimal duct obstruction (CNLDO).

Method: The medical records of patients who underwent nasolacrimal duct probing for CNLDO in ophthalmic theater of Al-Jamhori Teaching Hospital, between $1^{\text {st }}$ January 2009 and $31^{\text {st }}$ December 2010 were reviewed retrospectively. Nasolacrimal duct probing was performed on 76 eyes from 73 consecutive patients with CNLDO.

Results: Based on exclusion criteria, 76 eyes from 73 patients (30 males and 43 females), aged 6 to 84 months (mean, 15.67 \pm 13.58 ) were included. The success rate of the initial probing was $84.2 \%(64$ of 76$)$ for all patients, $92.15 \%$ (47 of 51) in the 6 to 12 month age group, $75 \%$ (12 of 16 ) in the 13 to 24 months age group, and $55.5 \%$ (5 of 9 ) among individuals older than 24 months.

Conclusion: The success rate of probing is very high in 6-12 months age group.

Keywords: Early probing, congenital obstruction, nasolacrimal duct.

\section{التسليك المبكر للإنسداد الخلقي للقناة الدمعية الأنفية}

$$
\text { فرع الجراحة، كلية الطب، جامعية الموصل، الموصل، العراق }
$$

$$
\begin{aligned}
& \text { الخلاصة } \\
& \text { الهُف: لتعميم عملية العلاج المبكر (بين ا_Y I شهر) بو اسطة تسليك المجرى الدمعي الأولي للمرضى المصابين بإنسداد المجرى }
\end{aligned}
$$

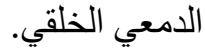

$$
\begin{aligned}
& \text { التصميم: در اسة تر اجعية لـ ( VT عين) أجريت لهم عملية تسليك المجرى الدمعي الأولي. }
\end{aligned}
$$

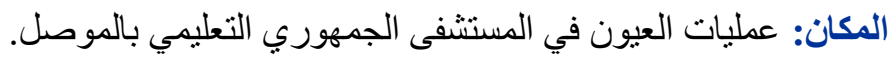

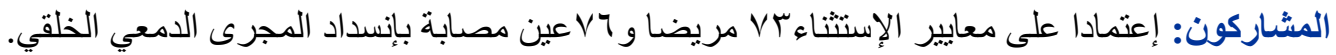

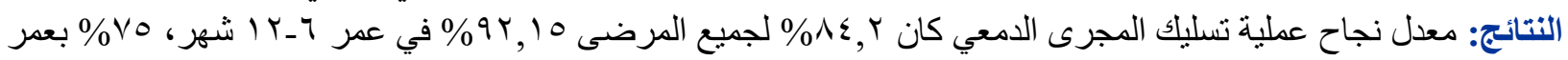

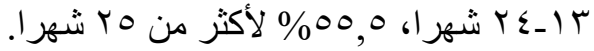

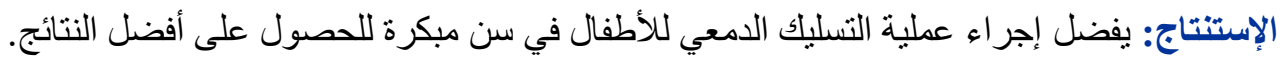

$$
\begin{aligned}
& \text { الكلمات المفتاحيه: تسليك مبكر ، الإنسداد الخلقي، القناة الأنفية الدمعية. }
\end{aligned}
$$

\section{INTRODUCTION}

T ear is secreted by lacrimal and accessory glands, circulate over the corneal and conjunctival surfaces, and is then pumped out to the punctum, from the punctum, tear flows through the canalicular system and emptie in the nasolacrimal sac. From there is travels through the nasolacrimal duct (NLD) and exists into the nasal cavity. ${ }^{1}$

The tear drainage was $25 \%$ by evaporation and the rest by excretion which is either passive by 
gravity and capillarity or active by lacrimal pump through the action of lacrimal portion of orbicularis oculi muscle (Horner's muscle). ${ }^{2}$

The (NLD) lies in maxillary bone. Obstruction of the nasolacrimal drainage system is extremely common in the pediatric age group, occurring in as many as $20 \%-30 \%$ of newborns and spontaneous resolution occurs in $80 \%-90 \%$ of affected infant by one year of age. ${ }^{3-6}$ In patients in whom the NLD fails to canalize the condition persists. The timing of probing for CNLDO has been a matter of controversy in recent years. When the condition persists beyond 6 months, early probing gives good results. An equally effective approach is conservative management until 9-12 months of age waiting spontaneous resolutions followed by probing for persistent obstruction. ${ }^{7}$

Traditional options include office probing with topical anesthesia at the age of 4 to 6 months or observation and medical management followed by probing under general anesthesia at approximately 12 months of age. ${ }^{8}$

It has been reported that delay in probing beyond 6 months is associated with lower rate of success and this worsens as the child gets older. ${ }^{7-9}$

Conversely, there are studies which indicate that primary probing continue to be an effective treatment well beyond 2 years of age and that the cure rate does not vary markedly with age..$^{7,10-13}$ There are thus no clear guidelines for management of CNLDO.

The aim of this study is to evaluate the result of early probing in children aged 6-12 months.

\section{MATERIALS AND METHODS}

The current study is a retrospective comparative case series of consecutive patients on whom the author performed nasolacrimal duct probing as the primary treatment method for CNLDO. The medical records of patients who underwent nasolacrimal duct probing at Al-Jamhori Teaching Hospital for CNLDO between $1^{\text {st }}$ January 2009 and31 ${ }^{\text {st }}$ December 2010 were reviewed retrospectively.

In total, nasolacrimal duct probing was performed on 82 eyes of 78 consecutive patients with CNLDO (3 patients bilateral). After enrollment, six eyes from 5 patients were excluded, leaving 76 eyes of 73 patients. Exclusion criteria included epiblepharon (2 eyes from 1 patients), acute dacryocystitis ( 1 eye), canalicular obstruction (1 eye), and loss to follow-up (2 eyes). Patients with previous history of probing were also excluded, as were patients with dacryocistitis (diagnosed by visualizing pus after digital sac compression).

Patients with congenital craniofacial and lid abnormalities, punctal agenesis, a history of trauma, nasolacrimal surgery, previous probing or other nasolacrimal intervention, and postoperative follow-up $<3$ months were excluded from the study.

Inclusion criteria were; no prior nasolacrimal surgical procedure, history of epiphora and/or discharge since birth or shortly after birth in one or both eyes and at least one of the following clinical signs: epiphora, to eliminate any other ophthalmological problem which may cause epiphora such as congenital glaucoma, trichiasis, conjunctivitis, keratitis, and metabolic disorders.

Prior to probing, enrolled subjects received medical treatment by lacrimal sac massage and/or topical antibiotics till $6^{\text {th }}$ month of age. Probing was done after failure of medical management.

The procedure of probing in all cases was performed in operating theater under general anesthesia by the author, probing was done via the lower punctum using standardized Bowman's probe.

In children younger than 36 months, an initial attempt was made using size $00(0.90 \mathrm{~mm}$ diameter), while size 0 probe $(1.00 \mathrm{~mm}$ diameter) was used in patients 37-48 months and sized (1.10 $\mathrm{mm}$ diameter) in patients older than 49 months after initial dilatation of lower punctum by fine punctual dilator.

The Bowman probe was inserted perpendicular to the lower eyelid margin reaching the ampulla. The probe was then rotated horizontally to the lower canicular and inserted toward the lacrimal sac at slightly upward angle, while lacrimal traction was applied to the eyelid, when a hard stop was felt, the probe was rotated 90 degree and advanced toward the NLD until a "popping" sensation is felt. The probe was then removed, and the patency of the lacrimal drainage system was confirmed by saline irrigation from lower punctum. Flow of saline in throat was confirmed by placing a pediatric size suction in throat or some time we do fluorescein dye disappearance test, ${ }^{14}$ by adding fluorescein stain to the tear.

Each patient received optiflox drop four times daily for 2 weeks. Patients were seen in the clinic 
at one week, one month, and 3 months after probing. Success of probing was the main outcome measure and was defined as a complete remission of watering, discharge and reflux of the lacrimal sac on pressure at one week of procedure.

\section{Statistical analysis}

Carried out by use of Chi-square analysis, the result considered significant if $P$-value was less than 0.05 .

\section{RESULTS}

Seventy six eyes from 73 patients were evaluated ( 3 individuals with bilateral CNLDO): the range included 30 males and 43 females. At the time of initial probing, patients ranged in age from 6 to 84 months (mean 15.67 $\pm 13.58 S D$ ).

The mean age of children in group 1 was $9.29 \pm$ 2.38 SD, group 2 was $19.31 \pm 4.37$ SD \& in group 3 was $45.33 \pm 19.46$ SD. The study period was from $1^{\text {st }}$ Jan 2009 to 31 Dec 2010. The success rate of probing was shown in Table 1.

The success rate in group 1 was $92.2 \%$ (47 of 51 ), in group 2 was $75 \%$ (12 out of 16) and in group $355.5 \%$ (5 out of 9 ), the success rate was the whole sample was $84.2 \%$. $\mathrm{P}$ value was 0.05 . None of the patients had any surgery or anesthesia-related complication.

There were two types of obstruction encountered during probing, simple and complex. In simple obstruction the resistance could be easily by passed with the help of the Bowman's probe and post probing syringing revealed a patent lacrimal system.

In complex obstruction however, the resistance could not be by passed and post probing syringing was not patent in any of these patients. ${ }^{15,16}$

Chi-square (4.87) analysis, showed significant difference in the cure rate with increasing age $(p=0.05)$.

Table 1. Success rate of primary probing for congenital naso-lacrimal duct obstruction in 76 eyes.

\begin{tabular}{lccc}
\hline $\begin{array}{c}\text { Age } \\
\text { (month) }\end{array}$ & Success rate & Failure rate & P-value \\
\hline 6-12 & $92.2 \%(47 / 51)$ & $7.8 \%(4 / 51)$ & 0.05 \\
$\mathbf{1 3 - 2 4}$ & $75 \%(12 / 16)$ & $25 \%(4 / 16)$ & 0.05 \\
$>\mathbf{2 5}$ & $55.5 \%(5 / 9)$ & $44.5 \%(4 / 9)$ & 0.05 \\
\hline \multicolumn{1}{c}{ Total } & $84.2 \%(64 / 76)$ & $15.8 \%(12 / 76)$ & significant \\
\hline
\end{tabular}

\section{DISCUSSION}

The lacrimal drainage system begins forming at approximately 6 weeks of gestational age as a depression termed the lacrimal groove.

A solid cord of ectoderm is eventually buried as the mesoderm develops and extends, from the eyelids to the nose. Canalization of cord begins at approximately 3.5 months of gestational age and is usually completed at or near the time of birth, with lower part of the system being the last to open.

Anomalies may occur anywhere along the course of system. ${ }^{5}$ Atresia of the NLD or dacryostenosis is the most common cause of epiphora in pediatric population. The most common site of obstruction is at the mucosal entrance into the nose (Valve of Hasner) under the inferior turbinate. ${ }^{3}$

Although NLD probing is a standard therapeutic procedure in the management of CNLDO, some controversy exists regarding the optimal timing of probing. In this study, the success rates were $92.15 \%$ (47 of 51 ) for group 1 (6-12 months), $75 \%$ (12 of 16) in group 2 (13-24 months) and 55.5\% (5 of 9 ) for individuals in group 3 (>25months). In similar study, Katowitz and Welsh, ${ }^{17}$ reported a probing success rates of $98.2 \%$ in subjects aged 0 6 months, $95.9 \%$ in subjects aged 7-12 months, $76.8 \%$ in subjects aged $13-18$ months, and $54.1 \%$ in subjects aged 19-24 months. Likewise the success rates in a study from Mannor et al ${ }^{18}$ were $92 \%$ for subjects aged $0-12$ months, $84.4 \%$ for subjects aged $13-24$ months, $65 \%$ for subjects aged $25-36$ months, and $63.5 \%$ for subjects aged 37-60 months.

The data from Ahn et al, ${ }^{19}$ the reported success rates with probing were $95.4 \%$ for subjects aged 35 months, $92.8 \%$ for subjects aged 6-8 months, $77.7 \%$ for subjects aged $9-11$ months, $72.7 \%$ for subjects aged $12-14$ months and $66.7 \%$ for $15 \geq$ months subjects, so the success rate increased when the procedure was done at earlier age.

Many factors are believed to affect the success rate of NLD probing. Age, bilaterality, prior failed probing attempt, prior failed conservative treatment, dilated sac and non-membranous CNLDO have all led to significant impact on probing success rate $(p<0.05) .{ }^{13}$ Similarly, new evidence also suggests, that concurrent fistula can reduce the probing success rate. ${ }^{20}$ 
Advocates of early probing suggest that early correction avoids months of morbidity due to epiphora and chronic dacryocystitis. They also suggest that postponement of the procedure may result in decreased success rate with simple probing because of chronic inflammation and secondary fibrosis. ${ }^{7,9,10}$

Some reports have suggested that the success rate of the intervention drops substantially in older children. ${ }^{9-11}$ More complicated and invasive procedures, such as silastic intubation or DCR, have been attempted in these individuals. ${ }^{21}$ So an early initial probing is a better policy to be adopted in our patients.

\section{CONCLUSION}

Probing is highly successful in the early age group (6-12 months), and should be adopted as a first line of treatment.

\section{REFERENCES}

1. Young JDH, Mac Ewen CJ. Managing congenital lacrimal obstruction in general practice. BMJ 1997; 15:293-6.

2. Cassidy TC. Developmental anatomy of the nasolacrimal duct. Arch Ophthalmol 1952; 47:141-58.

3. Piest KL, Katowitz JA. Treatment of congenital nasolacrimal duct obstruction. Ophthalmology Clinics of North America 1991; 4: 201-9.

4. Robb RM. Congenital nasolacrimal duct Obstruction. Ophthalmology clinics of North America 2001; 14: 443 46.

5. Kerstein RC. Congenital lacrimal abnormalities In: Principles and Practice of Ophthalmic Plastic and Reconstructive Surgery. WB Saunders Company; 1996; 2: 731-747.

6. James DH, MacEwen CJ. Managing congenital nasolacrimal duct obstruction in general practice. British Medical Journal 1997; 315: 293-96.

7. Honavar S, Vasudha EP, Rao GN. Outcome of probing for congenital nasolacrimal duct obstruction in older Children. Am J Ophthalmol 2000; 130: 42- 48.
8. Mannor GE, Rose GE, Kwabena FA, Eric Ezra. Factors affecting the success rate of nasolacrimal duct probing for congenital nasolacrimal duct obstruction. Am J Ophthalmol 1999; 127: 616-17.

9. Katowitz JA, Welsh MG. Timing of initial probing \& irrigation in congenital nasolacrimal duct obstruction.Ophthalmology 1987; 94: 698-705.

10. Stager D, Baker JD, Frey T, Weakley DR Jr, Birch EE. Office probing for congenital nasolacrimal duct obstruction. Ophthalmic Surg 1992; 23: 482-84.

11. Robb RM. Success rates of nasolacrimal duct probing at time intervals after 1 year of age. Ophthalmology 1998; 105: 1307-10.

12. Kushner BJ. Management of nasolacrimal duct obstruction in children between 18 months and 4 years old. J-AAPOS 1998; 2: 57-60.

13. Mansoury EJ, Calhoun JH, Nelson LB, Harley RD. Results of late probing for congenital nasolacrimal duct obstruction. Ophthalmology 1986; 93:1052-54.

14. Steindler $P$, Mantovani E, Incorvaia $C$, Parmeggiani F. Efficacy of probing for children with congenital nasolacrimal duct obstruction: a retrospective study using fluorescein dye disappearance test and lacrimal sac echography. Graefes Arch ClinExpOphthalmol. 2009; 247:837-846.

15. Limbu B, Akin M, Saiju R. Age-based comparision of successful probing in Nepalese children with nasolacrimal duct obstruction. Orbit. 2010; 29:16-20.

16. Choi WC, Kim KS, Park TK, Chung CS. Intranasal endoscopic diagnosis and treatment in congenital nasolacrimal duct obstruction. Ophthalmic Surg Lasers. 2002; 33:288-292.

17. Katowitz JA, Welsh MG. Timing of initial probing and irrigation in congenital nasolacrimal duct obstruction. Ophthalmology.1987; 94:698-705.

18. Mannor GE, Rose GE, Frimpong- Ansah K, Ezra E. Factors affecting the success of nasolacrimal duct probing for congenital nasolacrimal duct obstruction. Am J Ophthalmol.1999; 127:616-617.

19. Ahn DH, Lew H, Kim HY, Lee SY. The effect of probing for congenital nasolacrimal duct obstruction. $\mathrm{J}$ Korean Ophthalmol Soc.1998; 39:836-840.

20. Welham RA, Bergin DJ. Congenital lacrimal fistulas. Arch ophthalmol. 1985; 103:545-548.

21. Repka MX, Chandler DL, Beck RW, et al. Primary treatment of nasolacrimal duct obstruction with probing in children younger than 4 years. Ophthalmology. 2008; 115:577-584. 